\title{
접촉성 손-위치 반응(Contactual Hand-Orientating Response)이 만성 뇌졸중환자의 일어서기 동작에 미치는 영향
}

\author{
서태화 ${ }^{1}$, 양시은 ${ }^{2}$, 이홍균 ${ }^{*}$ \\ ${ }^{1}$ 광주여자대학교 물리치료학과, ${ }^{2}$ 상무힐링요양병원, ${ }^{*}{ }^{3}$ 동신대학교 물리치료학과
}

The Effects of Contact Hand-Orientation Response(CHOR) During Sit-to-stand(STS) in People with Stroke

\author{
Tae-Hwa Seo ${ }^{1}$, Si-Eun Yang ${ }^{2}$, Hong-Gyun Lee ${ }^{* 3}$ \\ 'Dept. of Physical Therapy, Kwangju Women's University \\ ${ }^{2}$ Dept. of Physical Therapy, Sangmu Healing Hospital \\ ${ }^{*}$ Dept. of Physical Therapy, Dongshin University
}

Purpose The purpose of this study was to investigate the effects of contact hand-orientation response(CHOR) during sit-to-stand(STS) in people with stroke. Methods The subjects of the study were Thirty hemiplegia participated (Rt. hemiplegia/Lt. hemiplegia: 15/15, mean age: $65.82 \pm 8.53$ ) in this study. The analysis of muscles activation (rectus femoris, biceps femoris, tibialis anterior, gastrocnemius) distribution was conducted by the EMG, and the analysis of foot pressure distribution was conducted by the resistive pressure sensor. Hemiplegic stroke patients were instructed to perform STS three times with the non-affected side hand and affected side hand on the table. Results There was a significant positive correlation between rectus femoris, tibialis anterior muscle activation and affected side hand contact during $\operatorname{STS}(p<0.05)$. The STS correlated with the foot pressure in the affected side hand $\operatorname{contact}(p<0.05)$. Conclusion AS a result, CHOR during STS is related to muscle activation and the characteristics of foot pressure. This information was observed in the affected side hand contact on the table, suggestion that rehabilitation programs should be implemented.

Key words CHOR, EMG, Foot pressure, Sit-to-stand, Stroke

Corresponding author Hong-Gyun Lee (leehonggyun@naver.com)

Received date 26 September 2018

Revised date 01 October 2018

Accepted date 01 October 2018

\section{I. 서 론}

뇌졸중이란 뇌에 공급되는 혈류의 차단으로 인해 뇌혈관의 허 혈 또는 출혈로 대뇌의 기능이 소실되어 다양한 증상이 동반 되는 질환이다. ${ }^{1)}$ 또한 신경학적 기능이 갑자기 소실되는 것으 로 성인에게 발생하는 장애 중 큰 어려움을 초래하는 중요한 원인이다. ${ }^{2)}$

뇌졸중으로 인해 발생하는 편마비환자의 일반적인 증상은 감각의 변화와 근육의 약화로 인해 몸통조절이 어렵게 되고, 보행 능력의 저하, 균형 감각 저하, 일상생활 동작의 어려움 등의 운동능력 장애가 발생하고, ${ }^{3)}$ 또한 마비측으로 체중 이동 이 감소하여 비대칭적 자세가 나타난다. ${ }^{4)}$ 운동능력 장애의 주 요한 증상 중 하나가 $61 \%-80 \%$ 를 마비쪽 하지보다 비마비측 에 편중되어 서는 것이다.")

일어서기 동작(Sit-to-stand; STS)은 앉은 자세에서 선 자

http:dx.doi.org/10.17817/2018.10.01.111319
세로 일어나는 동작으로 일상생활에서 가장 많이 이용되는 움 직임 중 하나이다. ${ }^{\natural}$ STS 동작 시 움직임을 조절하기 위한 넙 다리근의 구심성 수축과 뒤넙다리근의 원심성 수축을 통해 안 정적으로 수행될 수 있다. ${ }^{7)}$ 또한, STS 동작 시 앞정강근과 넙 다리근 질량 중심을 앞쪽과 위쪽으로 이동시키며, 넙다리뒤근 과 가자미근은 원심성 수축을 통해 STS 시 동작의 정도를 조 절한다. 엉덩이 떼기 시점 전 넙다리근과 앞정강근이 활성화 되며, 엉덩이 떼기 직후에 넙다리근이 활성화되어 STS 동작 시 중요한 역할을 한다. ${ }^{8)}$ 그러나 뇌졸중 환자는 정상인의 STS 시 몸통과 하지의 활동을 선택적이며, 동시에 요구하는 STS

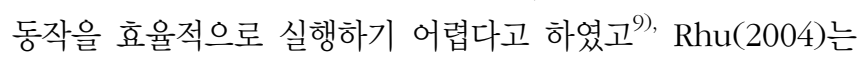
STS 동작 시 하지의 근력이 부족한 노인과 양 하지 움직임이 대칭적으로 수행이 어려운 편마비 환자들의 독립적인 생활과 일상생활 활동을 위한 필수적인 요소라고 하였다. ${ }^{10)}$

뇌졸중 환자들은 STS 동작 시 비대칭성을 보상하기 위해 엉덩이 떼기 시 체중을 비마비측으로 이동시키는 방법을 사용 
하거나, 비마비측 발을 마비측 발보다 뒤쪽에 위치하여 일어 나거나 팔을 사용한다. ${ }^{8)}$ 앞- 뒤와 안-바깥 방향의 무게중심 위 치가 일반인과는 다르며 ${ }^{11}$, 발 위치에 따라 STS 동작의 수행 능력이 다르게 나타났다. ${ }^{12)}$

STS 동작 동안 마비측과 비마비측의 대칭성을 향상시키기 위해서 체중이동을 강조하는 훈련을 이용하는 방법 ${ }^{13)}$, 마비측 에 강제적으로 체중을 싣게 하여 근육의 활동을 증가시키는 방법 ${ }^{14)}$, 상상 연습을 이용한 방법 ${ }^{15)}$, 발목관절 보조기를 이용 한 방법 ${ }^{16)}$, 불안정 지지면에서 일어서기 방법 ${ }^{17)}$ 등을 이용한 연구 방법 등이 있으나, 이러한 연구들은 편마비 환자의 양쪽 하지가 같은 형태에서 운동을 시행하거나, 양쪽 하지의 조건 을 바꾸어 운동을 시행하는 등의 국한된 방법들이 많았다.

Sue Raine 등(2013)은 접촉성 손-위치 반응(Contactual Hand-Orientating Response, CHOR)이 체간의 중심선 개 념 성립, 손목, 팔꿈치 및 어깨 동작을 조절하는데 필요한 자 세 안정화를 증진한다고 하였다. ${ }^{18)}$ 또한 Song 은 손 중심 체 감각 훈련을 통해 자세 조절 능력, 체간 안정성, 팔 기능과 손 감각 증진에 대해 효과를 입증하였다. ${ }^{19)}$

뇌졸중으로 인한 편마비 환자에게 양 하지의 불균형은 일 상생활 복귀에 큰 제한 요소이며, 독립적인 보행과 일상생활 을 위해 STS 동작 시 마비측과 비마비측의 대칭적인 수행은 꼭 필요하다.

따라서 본 연구에서는 편마비 환자의 접촉성 손-위치 반응 을 이용하여 비마비측 손을 테이블에 접촉한 상태에서 STS 동작을 하였을 때와 마비측 손을 테이블에 접촉한 상태에서 STS 동작을 하였을 때 근 활성도와 족저압에 미치는 영향을 분석함으로써 대칭적인 체중분포율과 하지의 근력을 증진 시 킬 방법을 모색하고, 편마비 환자의 STS 동작 훈련에 필요한 정보를 제공하고자 하였다.

\section{II. 연구 방법}

\section{1. 연구대상 및 기간}

본 연구는 광주 소재의 S요양 병원에 입원 중인 6개월 이상 된 만성 뇌졸중 환자 30 명을 대상으로 하였고 선정 조건은 다 음과 같다.

1) CT나 MRI로 뇌졸중으로 진단을 받고 6개월 이상 경과한 만성 뇌졸중 환자

2) 한국판 간이 정신 검사 점수가 24 점 이상으로 의사소통과 과제 이해가 가능한 환자

3) 양다리의 정형외과적 수술이나 장애로 인하여 보행에 문제 가 없는 환자

4) 혼자서 일어날 수 있고, 독립적인 서기 자세를 1 분 이상
Table 1. General characteristics of the subjects

\begin{tabular}{cccc}
\hline Agelyr) & Height(cm) & Weight(kg) & $\begin{array}{c}\text { Hemi-side } \\
\text { (R/L) }\end{array}$ \\
\hline $65.82 \pm 8.53$ & $163.83 \pm 8.44$ & $66.23 \pm 8.97$ & $15 / 15$ \\
\hline
\end{tabular}

지속할 수 있는 환자 ${ }^{20)}$

모든 조건을 충족하는 대상자를 30명 선정하였으며, 2018 년 9월 5일 부터 2018년 9월 7일간 총 3일에 걸쳐 측정 하 였다. 비마비측 손을 테이블에 접촉한 상태에서 STS 동작을 3 회 실시하였고, 2 분간 휴식 후 마비측 손을 테이블에 접촉한 상태에서 STS 동작을 3회 실시하여 평균값을 구하였다. 대상 자의 일반적인 특성은 아래에 나타났다(Table 1).

\section{2. 측정방법}

1) 표면 근전도(BTS Free EMG 1000)

근전도 측정은 표면 근전도(BTS Free EMG 1000)를 사용하 였다. 표면전극부착 부위는 넙다리곧은근(rectus femoris), 넙다리두갈래근(biceps femoris), 장딴지근(gastrocnemius), 앞정강근(Tibialis anterior)에 각각 부착 하였다. ${ }^{21)}$ 연구에서 는 STS 동작 시 엉덩이 떼기 시점을 기준으로 전과 후 각 0.5 초(총 1 초)를 포함하여 정하였으며, 3 번 측정 후 평균값을 산 출하여 분석하였다. 먼저 부착할 신체 부위를 노출시킨 후, 피 부 저항을 줄이기 위해 털을 제거하고 알코올로 닦은 후, 각 근육에 부착부위를 펜으로 표시하였다. 활성 전극 사이 거리 는 $2 \mathrm{~cm}$ 이내로 하였다.

수집된 표면 근전도 신호는 BTS EMG-Analyzer ver. 2.9.37.0 소프트웨어를 이용하여 처리하였다. 근전도 신호의 표본 추출률은 $1000 \mathrm{~Hz}$ 로 설정하였고 대역통과필터(Band pass filter)를 이용하여 20 500Hz로 필터링 하였으며, $60 \mathrm{~Hz}$ 노치필터를 사용하였다.

그리고 \%RVC 값을 산출하기 위해 각 근육의 자발적 기 준 수축 백분율 값은 선 자세를 기준으로 측정되었으며, 측정 한 데이터를 기준을 앞, 뒤 1 초간의 기록을 제외하였다.
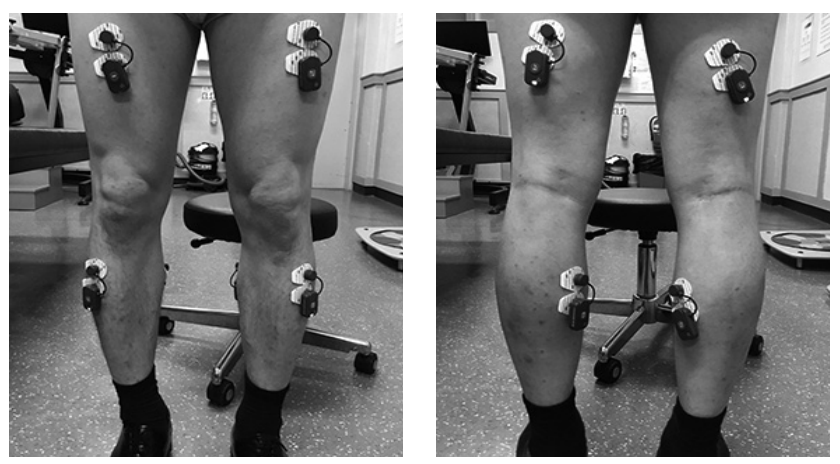

Figure 1. EMG 


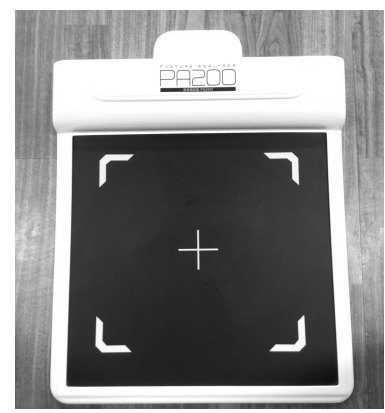

Figure 2. foot pressure

\section{2) 족저압 측정}

STS 동작을 하는 동안 발바닥에 가해지는 압력을 평가하기 위해 매트(mat) 형태의 저항식 압력 센서인 PA200을 사용하 였다. 압력 분포는 Shisei Innovation System Ver 8.62 을 이용하여 자료를 수집하여 분석하였다.

족저 압력 측정 장비는 압력 감지 센서가 장착된 판 위에 서 STS 동작이 끝난 정지 상태에서의 족저 압력 분포 상태를 측정하는데 발의 압력을 측정하여 양 하지의 대칭성 및 비대 칭성의 체중 이동과 편중 현상을 분석한다. 신체 균형 및 족 저압 분석은 양 발의 압력 차이를 측정하고 압력 분포를 그래 픽화 하여 분석하였다.

\section{4. 자료분석방법}

본 연구에서 얻어진 결과는 SPSS Statistics 18.0 통계 프로그 램을 이용하여 평균과 표준편차를 산출하였다. 대상자의 일반적
특성은 기술통계를 사용하였고, 집단 내 비교는 대응표본 $\mathrm{T}$ 검 정으로 분석하였다. 모든 통계학적 유의수준 $a=.05$ 로 하였다.

\section{III. 결 과}

\section{1. 근 활성도}

STS 동작 시 비마비측 손을 테이블에 접촉한 그룹에서 넙다 리곧은근에서 통계적으로 유의한 차이가 있었다 $(\mathrm{p}<.05)$.

넙다리두갈래근, 앞정강근, 장딴지근에서 통계적으로 유의 한 차이는 없었다 $(\mathrm{p}<.05)$.

STS 동작 시 마비측 손을 테이블에 접촉한 그룹에서 넙다 리곧은근과 앞정강근에서 통계적으로 유의한 차이가 있었다 ( $\mathrm{p}<.05)$.

넙다리두갈래근과 장딴지근에서 통계적으로 유의한 차이는 없었다(p>.05)(Table 2).

\section{2. 족저압 변화}

STS 동작 시 비마비측 손을 테이블에 접촉한 상태에서 실시 한 그룹에서 마비측과 비마비측 하지에 통계적으로 유의한 차 이가 있었다 $(\mathrm{p}<.05)$.

STS 동작 시 마비측 손을 테이블에 접촉한 상태에서 실시 한 그룹 사이에서 마비측과 비마비측 하지에 통계적으로 유의 한 차이가 있었다 $(\mathrm{p}<.05)$ (Table 3$)$.

Table 2. The changes of muscle activation according to hand positions during sit to stand

\begin{tabular}{|c|c|c|c|c|c|}
\hline & $\mathrm{A}$ & & B & $t$ & $P$ \\
\hline \multirow{4}{*}{ non Affected side } & $\mathrm{RF}$ & $407.56 \pm 74.41$ & $322.58 \pm 58.89$ & 2.123 & $0.042^{*}$ \\
\hline & $\mathrm{BF}$ & $117.05 \pm 21.37$ & $115.87 \pm 21.15$ & -1.54 & 0.134 \\
\hline & TA & $498.67 \pm 91.04$ & $400.30 \pm 73.08$ & 0.401 & 0.691 \\
\hline & GCM & $124.25 \pm 85.08$ & $131.59 \pm 98.46$ & -1.197 & 0.241 \\
\hline \multirow{4}{*}{ Affected side } & $\mathrm{RF}$ & $211.81 \pm 38.67$ & $487 \pm 50$ & -2.158 & $0.039 *$ \\
\hline & $\mathrm{BF}$ & $121.50 \pm 50.81$ & $161.50 \pm 188.50$ & -1.318 & 0.198 \\
\hline & TA & $434.35 \pm 351.24$ & $663.90 \pm 448.05$ & -3.292 & $0.003^{*}$ \\
\hline & GCM & $121.20 \pm 79.23$ & $130.26 \pm 90.78$ & -1.566 & 0.128 \\
\hline
\end{tabular}

${ }^{*} p<0.05, \mathrm{~A}$ : non Affected side hand contact, B : Affected side hand contact

RF : Rectus Femoris, BF : Biceps Femoris, TA : Tibialis anterior, GCM : Gastrocnemius

Table 3. Change of Foot Pressure

\begin{tabular}{cccccc} 
& & A & B & $t$ & $p$ \\
Weight bearing & non Affected side & $50.45 \pm 2.99$ & $48.43 \pm 3.77$ & 3.384 & $0.002^{*}$ \\
$(\%)$ & Affected side & $49.54 \pm 2.99$ & $51.46 \pm 3.66$ & -3.097 & $0.003^{*}$ \\
\hline
\end{tabular}

${ }^{*} p<0.05, \mathrm{~A}$ : non Affected side hand contact, B : Affected side hand contact 


\section{IV. 고 찰}

뇌졸중은 뇌 손상으로 인해 신경학적 기능 손상에 문제가 발 생하여 운동조절에 어려움이 나타나는 질환이다. ${ }^{22)}$

Camargos 등(2009)은 STS 동작은 일상생활에서 정상인 의 움직임 중 독립적인 삶을 살아가기 위해 꼭 필요한 동작이 라고 하였고, ${ }^{23)}$ 체간 근육들의 대칭적인 근 수행 능력과 양측 하지의 대칭적인 체중 지지가 필수적이라 하였다. ${ }^{24)}$

하지만 뇌졸중 환자들은 비마비측의 보상작용으로 인해 마 비측 체간 자세조절 능력의 감소하여 일어서기 과제의 수행을 어렵게 만들고, 척추에 불안정성을 일으키게 되어 자세 불균 형 및 불안정성을 초래하게 된다고 하였다. ${ }^{25)}$

Camargos 등(2009)은 뇌졸중 이후 STS 동작은 마비측과 비마비측 다리의 위치를 바꾸면서 동작 동안 마비측 다리에 앞정강근, 가자미근, 넙다리네갈래근, 뒤넙다리근의 근 활성도 뿐 아니라 일어나는데 걸리는 시간, 이동시간의 지연에 영향 을 받는다고 하였다. ${ }^{23)}$

Briere 등(2010)은 뇌졸중 환자 중 앉고 일어설 때 하지 의 비대칭적인 움직임 보이며, 대칭적인 움직임을 위해 치료 적 중재가 무엇보다 중요하다고 하였으며, ${ }^{26)}$ Yoon등(2009) 은 4주간 시각 차단 및 시각 되먹임을 적용한 STS 동작 훈련 이 아급성 뇌졸중 환자의 균형 능력을 향상하는데 효과가 있 다고 하였고 ${ }^{27)}$ Brunt등은 넙다리근과 앞정강근 활동 시 $\mathrm{EMG}$ 크기와 지면 반발력은 뒤에 있는 다리에서 유의한 증가 가 있는데, 이는 앞쪽 다리에서 지면 반발력이 감소하는 것과 일치한다. ${ }^{30)}$ 이는 마비측 발의 위치의 변화에 따라 마비측 하 지의 근 활성도를 높일 수 있음을 의미한다.

본 연구에서는 만성 뇌졸중 환자 30 명을 대상으로 STS 동 작 시 손 접촉 위치에 따른 근 활성도를 측정하였고, 힘판을 이용하여 족저압을 분석하였다. STS 동작 시 비마비측 손을 테이블에 접촉한 그룹보다 마비측 손을 테이블에 접촉한 그룹 에서 넙다리네갈래근과 앞정강근에서 유의한 차이를 보였으 며, 넙다리두갈래근과 장딴지근에서는 유의한 차이는 나타나 지 않았다. 이는 선행 연구에서 마비측 하지의 지면 반발력 향상이 넙다리네갈래근과 앞정강근 활동에 증가된 결과로 나 타났으며, 본 연구의 마비측 손이 테이블에 접촉한 상태에서 STS 동작을 했을 때 마비측 하지의 지면 반발력과 근 활성도 증가의 결과를 지지해주며, 통계적으로 유의한 차이가 나지 않는 장딴지근과 넙다리두갈래근은 STS 동작의 후기 단계에 서는 많은 영향을 주는 근육으로 본 연구에서 향상은 보였지 만 통계적으로 유의하지 않은 것을 보아 CHOR이 STS 동작 의 초기에 많은 영향을 미치는 것으로 보인다.

Cha 등(2010)은 성인 편마비 환자는 마비측이 비마비측 에 비해 보행 시 발바닥에 가해지는 전체 접촉면적과 족저압
중심의 전후 이동 경로 및 중족부에 가해지는 압력에서 낮은 분포를 보였으며, ${ }^{29)}$ Yoon등(2009)은 정상 성인과 편마비 환 자의 마비측과 비마비측의 보행 시 가해지는 족저압 분포를 비교해 본 결과, 발가락 영역과 발허리 영역, 발뒤꿈치 영역에 서 마비측이 비마비측보다 낮은 압력 분포를 보였다고 하였 다. ${ }^{30)}$

몸통 불균형과 몸통 회전이 비마비측의 평균 족저압과 체 중지지율에 유의한 결과를 보였다. 이는 몸통 불균형 값이 클 수록 몸통은 마비측으로 치우쳐진 것을 의미하며 이를 보상하 기 위해 목과 하부 몸통은 비마비측으로 편향되어 마비측 발 의 평균 족저압이 감소하여 비마비측 발의 평균 족저압과 체 중 지지율이 증가한 것으로 생각된다. ${ }^{31)}$

체중분배율 변화와 더불어 비마비측 발의 전방 족저압의 감소와 마비측 발의 접촉면의 의미 있는 증가는 체간의 항중 력 신전의 효과가 있다고 하였다. ${ }^{32)}$

선행 연구에 의하면 비마비측의 족저압의 감소와 마비측의 족저압의 증가는 편마비 환자에게 중요하다고 하였다. 따라서 뇌졸중 환자의 일상생활 활동의 제한점을 해결하기 위해 STS 동작의 개선이 필요하게 되는데, 하지의 근육의 근력과 적절 한 시기의 근수축, 체중지지비율의 대칭성 등의 조건이 필요 하다.

본 연구에서는 STS 동작 시 마비측 손을 테이블에 접촉한 그룹에서 비마비측 손을 테이블에 접촉한 그룹보다 마비측 하 지의 족저압에 유의한 증가를 보였다. 이는 편마비 환자의 족 저압이 마비측에 비해 비마비측에서 더욱 증가하는 것과 비대 칭적인 자세정렬이 지속되는 것에 대한 긍정적인 효과를 줄 수 있을 것으로 보인다. 또한 STS 동작 시 마비측 뿐만 아니 라 비마비측의 보상작용에 대한 연구의 기초 자료가 될 것으 로 생각된다.

\section{References}

1. Peurala SH, Kononen P, Pitkanen K, Sivenius J, et al. Postural instability in patients with chronic stroke. Restor Neurol Neurosci. 2007;25(2):101-108.

2. Adamson J, Beswick A, Ebrahim S. Is stroke the most common cause of disability? J Stroke Cerebrovasc Dis. 2004;13(4):171-177.

3. Verheyden G, Vereeck L, Truijen S, et al. Trunk performance after stroke and the relationship with balance, gait and function ability. Clin Rehabil. 2006;20(5):451-458.

4. Eng JJ, Chu KS. Reliability and comparison of weight-bearing ability during standing tasks for individuals with chronic stroke. Arch Phys Med Rehabil. 
2002;83(8):1138-1144.

5. Sackley CM, Baguly BI. Visual feedback after stroke with balance performance monitor: two single case studies. Clin Rehabil. 1993;7:189-195

6. Yoshioka S, Nagano A, Himono R, Fukashiro S. Computation of the kinematics and the minimum peak joint moments of sit-to-stand movements. Biomed Eng Online. 2007;3:6-26.

7. Canning CG, Shepherd RB, Carr JH, Alison JA, et al. A randomized controlled trial of the effects of intensive sit-to-stand training after recent traumatic brain injury on sit-to-stand performance. Clin Rehabil. 2003;17(4):355-362.

8. Carr JH, Shepherd RB. Stroke rehabilitation: guidelines for exercise and training to optimize motor skill: Butterworth-Heinemann. 2003:130-158.

9. Kim JM, LEE CH. Neurological physical therapy. Seoul: Jungdam. 2001.

10. Rhu YJ. Kinetic analysis of sit-to-stand movement in stroke patients. The Kor J Phy Edu. 2004;43(4):521-529.

11. Cheng PT, Liaw MY, Wong MK, Tang FT, et al. The sit-to-stand movement in stroke patients and its correlation with falling. Arch Phys Med Rehabil. 1998;29(9):1043-1046.

12. Lecours J, Nadeau S, Gravel D, Teixera-Salmela L. Interaction between foot placement, trunk frontal position, weight-bearing and knee moment asymmetry at seat-off during rising from a chair in healthy controls and persons with hemiparesis. J Rehabil. 2008;40(3):200-207.

13. Roy G, Nadeau S, Gravel D, Piotte F, et al. Side difference in the hip and knee joint moments during sit-to-stand and stand-to-sit tasks in individuals with hemiparesis. Clin Biomech. 2007;22(7):795-804.

14. Chaudhuri S, Aruin AS. The effect of shoe lifts on static and dynamic postural control in individuals with hemiparesis. Arch Phys Med Rehabil. 2000;81(11): 1498-1503.

15. Oh DW, Kim JS, Kim SY, Yo EY, et al. Effect of motor imagery training on symmetrical use of knee extensors during sit-to-stand and stand-to-sit tasks in post-stroke hemiparesis. Neuro Rehabil. 2010;26(4):307-315.

16. Park ES, Park CI, Chang HJ, Choi JE, et al. The effect of hinged ankle-foot orthoses on sit-to-stand transfer in children with spastic cerebral palsy. Arch Phys Med Rehabil. 2004;85(12):2053-2057.
17. Park J, Woo YK, Park SY. Effects of Sit-to-Stand Training on Unstable Surface on Balance in Subject With Stroke. Kor Rese Soc Phys Ther. 2013;20(3):1-8

18. Raine S, Mezdows L, Lynch-Ellerington M. The Bobath Concept: Theory and clinical pratice in neurological rehabilitation. 2013.

19. Song BK. Effect of Somatosensory Stimulation on Upper Limb in Sensory, Spatial neglect and Body Orientation within Unilateral Neglects after a Stroke. 2012;6(4):204-210.

20. Bensoussan L, Viton JM, Schieppati M, Collado H, et al. Changes in postural control in hemiplegic patients after stroke performing a dual task. Arch Phys Med Rehabil. 2007;88(8):1009-1015.

21. Cheng PT, Chen CL, Wang CM, Hong WH. Leg muscle activation patterns of sit-to-stand movement in stroke patients. Am J Phys Med Rehabil. 2004;83(1):10-16.

22. Dickstein R, Shefi S, Marcovitz E, Villa Y. Electromyographic activity of voluntarily activated trunk flexor and extensor muscles in post-stroke hemiparetic subjects. Clin Neurophysiol. 2004;115(4):790-796.

23. Camargos AC, Rodrigues-de-Paula-Goulart F, Teixeira-Salmela LF. The effects of foot position on the performance of the sit-to-stand movement with chronic stroke subjects. Arch Phys Med Rehabil. 2009;90(2):314-319.

24. Goulart FR, Valls-Sole J. patterned electromyographic activity in the sit-to-stand movement. Clin Neurophysiol. 1999;110(9):1634-1640.

25. Wagenaar RC, van Emmerik REA. Dynamics of pathological gait. Hum Mov Sci. 1994;13(3-4):441-471.

26. Briere A, Lauziere S, Gravel D, Nadeau S. Perception of weight-bearing distribution during sit-to-stand tasks in hemiparetic and healthy individuals. Stroke. 2010;41(8):1704-1708.

27. Yoon HS, Hwang BY. The effects of sit-to-standing training combined with visual intervention training on balance in the subacute stroke patients. J Korean Soc Neur Ther. 2017;21(2):15-19

28. Brunt D, Greenberg B, Wankadia S, Trimble MA et al. The effect of foot placement on sit to stand in healthy young subjects and patients with hemiplegia. Arch Phys Med Rehabil. 2002;83(7):924-929.

29. Cha YJ, Kim K. The comparison of plantar pressure distribution regarding the extent of hemineglect in adult 
hemiplegia. J Kor Med Sci. 2010;5(1):43-51.

30. Yoon HW, Lee SY, Lee HM. The comparison of plantar foot pressure in normal side of normal people, affected side and less affected side of hemiplegic patients during stance phase. The Kor Soc Phy Med. 2009;4():87-92.

31. Yang DJ, Park SK, Kang JI, Park SB. Effects of changes in postural alignment on foot pressure and balance of patients with stroke. J korean Soc Phys Ther. 2014;26(4):226-233.
32. Chang WN, Kim JH, Hwang BY. Effect of trunk facilitation based on the bobath concept on trunk alignment and weight distribution in patients with stroke. J Korean Soc Neur Ther. 2017;21(3):1-7. 